\title{
Oil Extraction and Compound analysis of Microalgae Chlorella vulgaris
}

\author{
T Mohan Viswanathan, Sundaresan Hemapriya, Shankar Sriga, Prokshan Bazeera Ferdhous, \\ Thandavarayan Kathiresan
}

\begin{abstract}
Microalgae gives the great impression being to be a prominent source biomass for oil production that has the capacity of downright the fossil fuel. In this earth's surface is protected with $80 \%$ of water, so microalgae would truly be inexhaustible option of prospect for the environment needs. Microalgae have been suggested as a promising oil feed stock and have been called the third-generation feedstock. In this study, we talk about the unique and relational valued prospect of C. vulgaris and also highlights the biomass, oil extraction, solvent system and compound properties. The reflux extraction method was used to extract oil from $C$. vulgaris. The oil extraction of $C$. vulgaris biomass using heptane as a dissolvable at the following optimum condition, stirring rate of 700 RPM, temperature of $85^{\circ} \mathrm{C}$ and extraction time at 6 hours. Then the compounds present in oil were anatomized by GCMS studies.
\end{abstract}

Keywords-Microalgae, C. vulgaris, heptane, GCMS

\section{INTRODUCTION}

Single celled microscopic photosynthetic organism microalgae that are constituted in both marine and freshwater environments. Photosynthetic execution of microalgae is corresponding to specific plant domains and they have mechanism is similar to land based plants, but due to a subnormal cellular structure, and being underwater in an aqueous environment where they have effectual access to major nutrients for their growth, they are more broadly effective in reconverting the energy source. A microalga is unilateral or ventricular organisms ranging in size from one or two microns to hundreds of microns that egresses either distinctly or as sequence or group, in both marine and aqueous environment. Algae is accepted as one of the familiar in worldwide (1). Microalgae have conventional, large indefinite quantity of consideration as another generator of inexhaustible energy in the form of oil (2). Oil extraction from microalgae from is a process that is commonly developed by high energy consumption and most

Revised Manuscript Received on December 29, 2019.

* Thadavarayan Kathiresan

T Mohan Viswanathan*, Department of Biotechnology, School of Bio and Chemical Engineering, Kalasalingam Academy of Research and Education, Krishnankoil, Virudhunagar Dt., Tamilnadu PIN 626126, India. Email: viswasonofmohan9@gmail.com

Sundaresan Hemapriya, Department of Biotechnology, School of Bio and Chemical Engineering, Kalasalingam Academy of Research and Education, Krishnankoil, Virudhunagar Dt., Tamilnadu PIN 626126, India.

Shankar Sriga. Department of Biotechnology, School of Bio and Chemical Engineering, Kalasalingam Academy of Research and Education, Krishnankoil, Virudhunagar Dt., Tamilnadu PIN 626126, India.

Prokshan Bazeera Ferdhous, Department of Biotechnology, School of Bio and Chemical Engineering, Kalasalingam Academy of Research and Education, Krishnankoil, Virudhunagar Dt., Tamilnadu PIN 626126, India. valuable deliberate content as of now since this valuable procedure is one of the numerous costly execution which can introduce property of green growth depended oil creation. A few systems to separate the oil from microalgae are open such as Expeller pressing, Bead beating, solvent extraction and fluid extraction (3). Expeller pressing is the strategy of separating oil with a mechanical press as opposed to overdrive the compound extraction procedure and this technique underwrite the yields just $65-70 \%$ (4). Chlorella $\mathrm{sp}$, is the important microalgae reservoir that is commonly used to produce algal oil, because the microalgae produce the huge amount oil content (\% dry weight) among the other microalgae with $60-70 \%$ oil substance created (5).

The extraction system is a standard and best methodology for conveying oil generation with the usage of extraordinary solvents to deliver much better measure of oil yield from microalgae. Since it is recover practically all the oil behind in excess of a $1 \%$ leftover oil in the crude material (6). In increase, this strategy, significantly low moderate employable expense arch with other oil creation (7).

Gas chromatography-mass spectrometry (GC-MS) presents an inferior method for compound investigation present in an algal oil. This method highlights all the various compounds present in an oil extract $(8,9)$. The mass spectrometry, which one can acquire a great extent detailed picture of specific compounds within specific species (10). In this research, the microalga $C$. vulgaris was utilized to produce oil. The microalgae were grown in a prevalent room temperature with light source, and separation technique was used for the oil extraction. The results point out that industrial operation might be economically and environmentally supportable.

\section{MATERIALS AND METHODS}

\section{A.Microalgae}

In this research the microalgae $C$. vulgaris was used to study of oil extraction. A microalgae strain was collected from the phycospectrum environmental research Center, Chennai. In algal research the microalgae $C$. vulgaris, which was most great in oil extraction and lipid creation it have a high lipid substance and viably created in the lab (11).

\section{B.Media Preparation}

The microalgae $\mathrm{C}$. vulgaris were literally cultured in Bold's Basal Medium with nitrogen, carbon and vitamin source by adding $10 \mathrm{~mL}$ of Macronutrients, $6 \mathrm{~mL}$ of Micro Nutrients, and $1 \mathrm{~mL}$ each of Vitamins (B1 and B12) to 1000 


\section{Oil Extraction and Compound analysis of Microalgae Chlorella vulgaris}

$\mathrm{mL}$ sterilized distilled water (DW). The media components are listed to table 1 .

\section{TABLE 1: Media components}

\begin{tabular}{|c|c|c|c|}
\hline S.No & $\begin{array}{c}\text { Type of } \\
\text { Nutrients }\end{array}$ & Chemicals & $\begin{array}{c}\text { Quantity } \\
\text { (g/l) }\end{array}$ \\
\hline \multirow{3}{*}{1} & & $\mathrm{NaNO}_{3}$ & 75 \\
& Macro & $\mathrm{CaCl}_{2} \cdot 2 \mathrm{H}_{2} \mathrm{O}$ & 2.5 \\
& Nutrients & $\mathrm{MgSO}_{4} \cdot 7 \mathrm{H}_{2} \mathrm{O}$ & 7.5 \\
& & $\mathrm{~K}_{2} \mathrm{HPO}_{4} \cdot 3 \mathrm{H}_{2} \mathrm{O}$ & 17.5 \\
& & $\mathrm{NaCl}^{2}$ & 2.5 \\
\hline \multirow{3}{*}{2} & & $\mathrm{FeCl}_{3} \cdot 6 \mathrm{H}_{2} \mathrm{O}$ & 0.97 \\
& & $\mathrm{MnCl}_{2} \cdot 4 \mathrm{H}_{2} \mathrm{O}$ & 0.41 \\
& Micro & $\mathrm{ZnCl}_{2}$ & 0.05 \\
& & $\mathrm{CoCl}_{2} \cdot 6 \mathrm{H}_{2} \mathrm{O}$ & 0.02 \\
& & $\mathrm{Na}_{2} \mathrm{MoO}_{4} \cdot 2 \mathrm{H}_{2} \mathrm{O}$ & 0.04 \\
\hline 3 & & $\operatorname{vitamin~B1}$ & 1 \\
& & vitamin B12 & 1.2 \\
\hline
\end{tabular}

\section{C.Culture Preparation}

The Microalgae culture medium preparation progress was finished by utilizing aseptic condition to maintain a strategic from any sullying. The medium containing flasks were sterilized in an autoclave, for 15 minutes at $121^{\circ} \mathrm{C}$. Then, 5 to $10 \mathrm{~mL}$ of microalgae stock culture was added into $2 \mathrm{~L}$ flasks loaded up with $1 \mathrm{~L}$ of autoclaved medium that contained all nutrients at room temperature. The lamp were utilized for nonstop lighting and refined with much of the time circulated air through for 15-18 days.

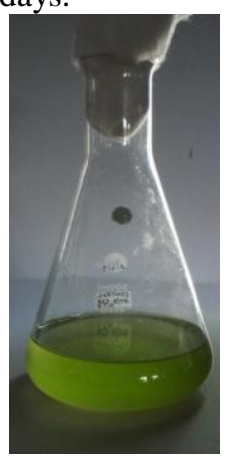

Fig 1: 18 days old culture of $C$. vulgaris

\section{D.Culture Harvesting and Biomass collection}

The $C$. vulgaris biomass was collected using centrifuge at $10000 \mathrm{rpm}$ for 10 minutes. After centrifugation, the supernatant was disposed and the subsequent pellet of $\mathrm{C}$. vulgaris biomass was washed twice with Millipore water to expel unconsumed supplements. The extracted biomass was dried with use of hot-air oven for overnight at $40-45^{\circ} \mathrm{c}$. Therefore, the dried microalgae biomass was used to oil extraction process. Dried biomass was measured for the yield determination.

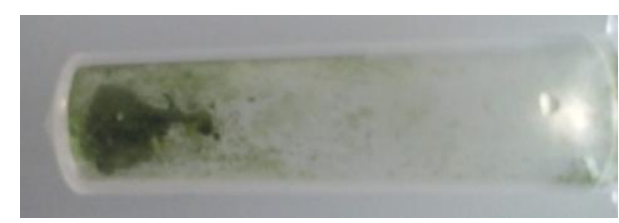

Fig 2: Cell dry biomass of $C$. vulgaris

\section{E.Destruction of cells}

$0.04 \mathrm{~g}$ of C. vulgaris powdered biomass alongside $16 \mathrm{~mL} \mathrm{DW}$ were set into $250 \mathrm{~mL}$ of measuring beaker and afterward sonicated for 10 minutes to destruct the cells (12).

\section{F. Oil extraction}

Reflux extraction technique was utilized in the oil extraction process. Extraction process for the most part containing the accompanying contraption: attractive magnetic pellets, hot plate stirrer, $1 \mathrm{~L}$ beaker, tube and $250 \mathrm{~mL}$ round base carafe. Around $28 \mathrm{~mL}$ of dissolvable was utilized for $0.04 \mathrm{~g}$ of the dried microalgae biomass in extraction step. The dissolvable heptane was utilized to extricate the oil from the $\mathrm{C}$. vulgaris biomass and the extraction occurred around 6 hours to separate oil from microalgae. Attractive stirrer was utilized to blend the biomass with the dissolvable at blending rate of $700 \mathrm{rpm}$ and temperature of $85^{\circ} \mathrm{C}$. Following 6 hours of extraction, the blend was then centrifuged at $8000 \mathrm{rpm}$ for 10 minutes and brought about partition into three layers (12). The upper layer comprises of oil-dissolvable blend, while center layer was biomass and most minimal layer of the division was water. The upper layer was gathered and dissipated using rotary evaporator to accomplish the microalgae oil.

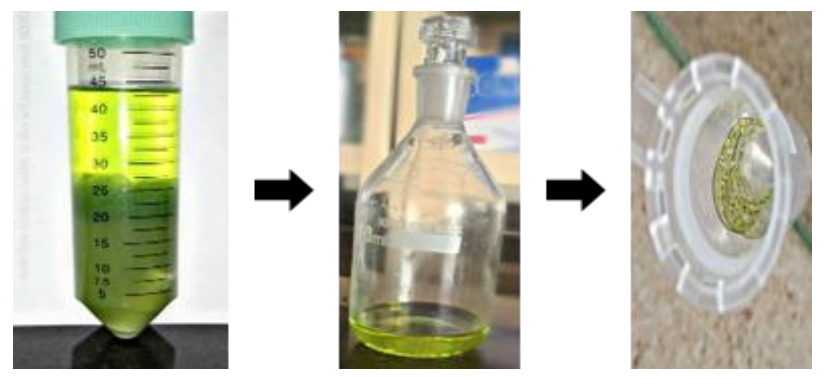

Fig 3: Extraction of oil from solvent mixture

\section{G. Determination of Yield}

After the oil extraction, the measure of oil yield was controlled by the following mathematical

$$
\text { Oil efficiency }(\%)=\frac{\text { Mass of extraction }(g)}{\text { Mass of driad bionass }(g)} \times 100(\%)
$$

\section{H. GC-MS analysis of Algal oil}

The GC-MS analysis was done at Ayya Nadar Janaki Ammal College, Sivakasi. GC-MS consider was actualizing to explore the mixes present in algal oil. The Gas Chromatography-Mass Spectrometry instrument separate synthetic mixture and recognizes the parts at a sub-atomic dimension. It is a standout amongst the most credible devices for research natural examples. The GC takes a shot at the rule that a mixture will isolate into individual substances when heated particularly organic examples. The information get to is the pinnacle zone that is relative to fixation and normal for maintenance time. The maintenance time is estimated by the recorder as the time between the minute you press begin and the time the finder sees the peak. We gave the oil content that we

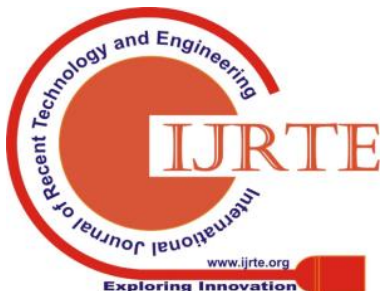


got to from the top layer to GC-MS examination with lipid section.

The aftereffects of GC-MS were explored beneath.

\section{RESULT}

\section{A.Effect of Solvent in Oil extraction}

The nonpolar, nontoxic dissolvable of heptane was utilized for the oil extraction from microalgae and it was demonstrated the exceptional returns of oil creation. The oil extraction yield of $99.5 \%$ was accomplished from C. vulgaris biomass when utilizing heptane as a dissolvable. This examination results may be hope to the next dissolvable's physical and synthetic trademark interest the nature of heptane to extricate the oil. Along these lines, the heptane was one of the more proficient dissolvable to extract the oil from microalgae.

TABLE 2: Solvent system effect on oil yield (\%)

\begin{tabular}{|c|c|c|c|c|}
\hline S.No & $\begin{array}{c}\text { Biomass } \\
(\mathrm{gms})\end{array}$ & $\begin{array}{c}\text { Solvent } \\
\text { system }\end{array}$ & $\begin{array}{c}\text { Yield } \\
(\mathrm{gms})\end{array}$ & $\begin{array}{c}\text { Yield } \\
(\%)\end{array}$ \\
\hline 1 & 0.04 & Heptane & $\begin{array}{c}0.039 \\
8\end{array}$ & 99.5 \\
\hline
\end{tabular}

e dissolvable heptane for oil extraction is a significant factor to deliver the most astounding yield of oil creation. Particularly, in algal oil extraction the dissolvable heptane, which comprises the capacity of incredible dissolvability with oil and potential to initiate the dominant part oil creation (13).

Be that as it may, when heptane was utilized to remove the oil, the yield of oil extraction become exceptionally high. Furthermore, the outcome demonstrated that a high productivity of oil extraction in heptane dissolvable. The oil extraction yield was turned out to be exceptionally higher when utilizing heptane for oil extraction.

\section{B.Compound analysis by GC-MS}

The database NIST was utilized to understanding on mass range was directed by GC-MS. The library NIST having in excess of 64,511 examples of Mass Spectrum Data. The obscure compound of range was broke down with the known compound of range put away in the library. The compound name, Molecular equation, atomic load of the compound to be tried and investigated.

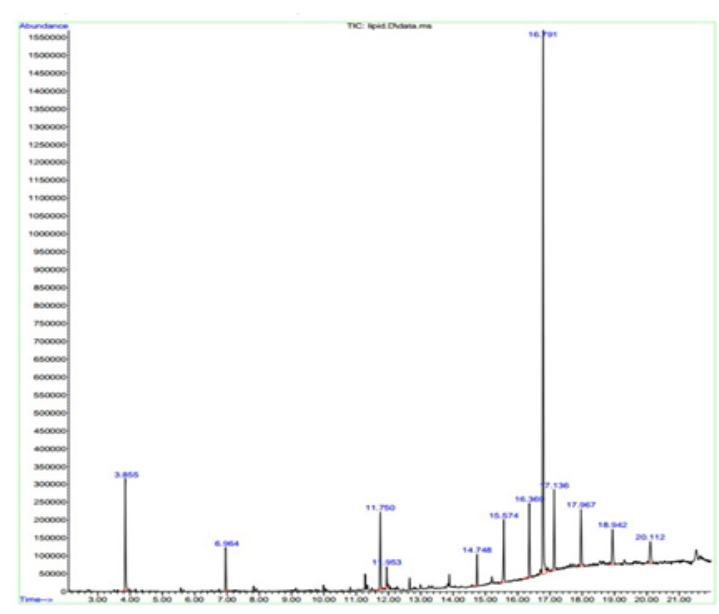

Fig 4: GC-MS spectrum of the heptane extract of $C$. vulgaris

TABLE 2: Bioactive Compounds present in heptane extraction of $C$. vulgaris

\begin{tabular}{|c|c|c|c|c|}
\hline S.No & Compound Name & $\begin{array}{c}\text { Molecular } \\
\text { Formula }\end{array}$ & Molecular weight & $\begin{array}{c}\text { Percentage } \\
\text { composition }\end{array}$ \\
\hline 1 & Benzaldehyde & $\mathrm{C}_{7} \mathrm{H}_{6} \mathrm{O}$ & $106.12 \mathrm{~g} / \mathrm{mol}$ & 3.855 \\
\hline 2 & Phenol 2,3- bis( dimethyl) & $\mathrm{C}_{14} \mathrm{H}_{22} \mathrm{O}$ & $368.56 \mathrm{~g} / \mathrm{mol}$ & 6.966 \\
\hline 3 & Dibutyl phthalate & $\mathrm{C}_{16} \mathrm{H}_{22} \mathrm{O}_{4}$ & $278.34 \mathrm{~g} / \mathrm{mol}$ & 11.750 \\
\hline 4 & Phthalic acid & $\mathrm{C}_{8} \mathrm{H}_{6} \mathrm{O}_{4}$ & $166.14 \mathrm{~g} / \mathrm{mol}$ & 11.949 \\
\hline 5 & Eicosane & $\mathrm{C}_{20} \mathrm{H}_{42}$ & $282.54 \mathrm{~g} / \mathrm{mol}$ & 14.748 \\
\hline 6 & Eicosane & $\mathrm{C}_{20} \mathrm{H}_{42}$ & $282.54 \mathrm{~g} / \mathrm{mol}$ & 15.570 \\
\hline 7 & Eicosane & $\mathrm{C}_{20} \mathrm{H}_{42}$ & $282.54 \mathrm{~g} / \mathrm{mol}$ & 16.364 \\
\hline 8 & Phthalic acid & $\mathrm{C}_{8} \mathrm{H}_{6} \mathrm{O}_{4}$ & $166.14 \mathrm{~g} / \mathrm{mol}$ & 16.790 \\
\hline 9 & Eicosane & $\mathrm{C}_{20} \mathrm{H}_{42}$ & $282.54 \mathrm{~g} / \mathrm{mol}$ & 17.140 \\
\hline 10 & Eicosane & $\mathrm{C}_{20} \mathrm{H}_{42}$ & $282.54 \mathrm{~g} / \mathrm{mol}$ & 17.962 \\
\hline 11 & Octadecane & $\mathrm{C}_{18} \mathrm{H}_{38}$ & $254.5 \mathrm{~g} / \mathrm{mol}$ & 18.946 \\
\hline 12 & Bromoeicosane & $\mathrm{C}_{8} \mathrm{H}_{17} \mathrm{Br}$ & $361.45 \mathrm{~g} / \mathrm{mol}$ & 20.109 \\
\hline
\end{tabular}

The outcome demonstrated most elevated pinnacle of creation 16.791 for phthalic acid. Eicosane was another exacerbate that was discovered most regular 14.748. Phthalic acid contain the property of plasticizers which is most normally present in the oil bundles. Another compound Eicosane which is antecedent of Omega 3 fatty acid. It can't be incorporated by our body and consequently it is eatable.

\section{Conclusion}

The extraction of oil from Chlorella vulgaris biomass utilizing heptane demonstrated the elevated yield of the oil $99.5 \%$ was acquired with ideal states of blending rate of 700 $\mathrm{rpm}$, temperature of $85^{\circ} \mathrm{C}$ and 6 hours of extraction time from $C$. vulgaris. The consistent oil yield separated from microalgae is on the grounds that the extraction has gone fulfillment by then. Extraction procedure ought not to be done at higher temperature to keep away from the decay of the microalgae which will influence the consequence of oil yield got. The nearness of the huge number and increment in least quality over 15 of hydrocarbons contrasted with the quantity of different parts in the concentrate recommends that the example is a potential wellspring of algal oils. Then, the algal oil compounds are identified using GC-MS. The compounds phthalic acid and Eicosane are regularly present in that analysis. The compound Eicosane and Phthalic acid are used in plastic industry. Accordingly, this examination has built up the Chlorella vulgaris strain utilizing atomic strategies and furthermore had the option to grandstand the possibilities of utilizing this 


\section{Oil Extraction and Compound analysis of Microalgae Chlorella vulgaris}

green growth as an elective wellspring of oil preparations and industry applications.

\section{REFERENCE}

1. P. Falkowski, J. A. Raven, “Aquatic Photosynthesis”, Malden. Mass. Blackwell Science: (1997), 375.

2. M. A. Islam, R. J. Brown, I. O'Hara, M. Kent, and K. Heimann, "Effect of temperature and moisture on high pressure lipid/oil extraction from microalgae". Energy Conversion and Management, (2014), 88: 307 316.

3. Nurfarahanim Abdullah, Nur Amelia Amran, Nur Hidayah Mat Yasin, "Algae oil extraction from freshwater microalgae C. vulgaris", Malaysian Journal of Analytical Sciences, (2017), 21(3), 735-744

4. H. Weingarten, "What is expeller and why does it matter. Retrieved from http://blog.fooducate.com/2010/12/08/what-is-expeller-pressed-oil-andwhy-does-itmatter/http://biofuel

org.uk /second-generation-biofuels.html". Date access 25 November 2015.

5. Y. Chisti, "Biodiesel from microalgae". Biotechnology Advances, (2007), 25, 294-306.

6. S. T. Niraj, J. R. Sunita, V. C. Renge, V. K. Satish, Y. P. Chavan, and S L. Bhagat, "Extraction of oil from algae by solvent extraction and oil expeller method”. International Journal Chemical Science, (2011), 9(4), 1746-1750.

7. A. L. Ahmad, N. H. Mat Yasin, C. J. C. Derek, and J. K. Lim, "Microfiltration of Chlorella sp.: Influence of material and membrane pore size". Membrane Water Treatment, (2013), 4(2), 143-155

8. J. Nordback, E. Lundberg, and W. W. Christie, "Separation of lipid classes from marine particulate material by HPLC on a polyvinyl alcohol-bonded stationary phase using dual-channel evaporative light scattering detection". Mar Chem, (1998), 60, 165-175

9. M. Graeve and D. Janssen, "Improved separation and quantification of neutral and polar lipid classes by HPLC-ELSD using a monolithic silica phase: application to exceptional marine lipids". J Chromatogr B (2009). $877,1815-1819$

10. K. M. MacDougall, J. McNichol, P. J. McGinn, S. J. O’Leary and J. E. Melanson, "Triacylglycerol profiling of microalgae strains for biofuel feedstock by liquid chromatography-high-resolution mass spectrometry". Anal Bioanal Chem (2011), 401, 2609-2616

11. A. L. Ahmad, N. H. Mat Yasin, C. J. C. Derek, and J. K. Lim, "Chemical cleaning of a cross-flow microfiltration membrane fouled by microalgal

\section{AUTHORS PROFILE}

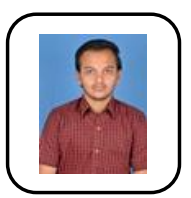

T Mohan Viswanathan, is a $\mathrm{PhD}$ Scholar in Kalasalingam Academy of Research and Education.

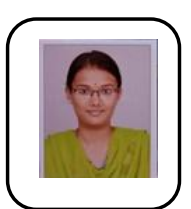

Sundaresan Hemapriya, Persuding B.Tech in Kalasalingam Academy of Research and Education, Krishnankoil.

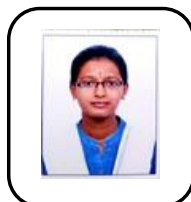

Shankar Sriga, B.Tech in Kalasalingam Academy of Research and Education, Krishnankoil.

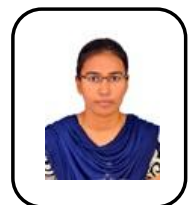

Prokshan Bazeera Ferdhous, B.Tech in Kalasalingam Academy of Research and Education, Krishnankoil

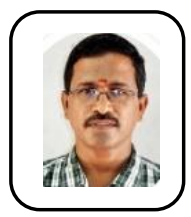

Thandavarayan Kathiresan, currently works at the Professor, Department of Bio-Technology, Kalasalingam Academy o Research and Education. biomass". Journal of Taiwan Institute of Chemical Engineers, (2014), 45, 233-241

12. A. L. Ahmad, N. H. Mat Yasin, C. J. C. Derek, and J. K. Lim "Comparison of harvesting methods for microalgae C. vulgaris sp. and its potential use as a biodiesel feedstock". Environmental Technology, (2016), 35(17-20), 2244-2253.

13. 13. M. Rezaie, R. Farhoosh, M. Iranshahi, A. Sharif, and S. Golmohamadzadeh, "Ultrasonic- assisted extraction of antioxidative compounds from Bene (Pistacia atlantica subsp. Mutica) hull using various solvents of different physicochemical properties". Food Chemistry, (2015), 173, 577-583. 